\title{
Optimization of a Motorcycle Rear Suspension Mechanism with Four-bar Linkage
}

\author{
Štefan Segla ${ }^{1 *}$, Ovidiu Antonescu ${ }^{2}$, Martin Orečný ${ }^{1}$, Abdel Elbaghar ${ }^{1}$ \\ 'Technical University of Košice, Faculty of Mechanical Engineering, Letná 9, 04200 Košice Slovakia \\ ${ }^{2}$ Politehnica University of Bucharest, Engineering and Management of the Technological Systems Faculty, Splaiul Independentei nr. 313, Bucharest
}

\begin{abstract}
Štefan Segla, prof. Ing. CSc. He received M.S. degree in Applied Mechanics from the Czech Technical University in Prague, Czechoslovakia, in 1978, CSc. degree received in Mechanics of Rigid and Deformable Bodies and Media from the Slovak Academy of Sciences, Slovakia, 1989. He is Professor of Mechanical Engineering at the Department of Applied Mechanics and Mechanical Engineering of the Faculty of Mechanical Engineering, Technical University of Košice, Slovakia. His research interests include vibroizolation of mechanical and mechatronical systems, vibration control, modelling and optimization of mechanical and mechatronical systems and static and dynamic balancing of robots, manipulators and rotating machines. He is a member of IFTOMM (International Federation for the Theory of Machines and Mechanisms) Permanent Commission A for Terminology and also IFToMM Technical Committee for Multibody Dynamics, member of the Czech Society for Mechanics, Slovak Society for Mechanics and also CEACM (Central European Association for Computational Mechanics). He has authored more than 150 journal and conference papers on these topics.
\end{abstract}

Ovidiu Antonescu, assoc. prof. Dr. Ing. He received M.S. degree in Mechanical Engineering, specialization of Automotive Engineering, from the Politehnica University of Bucharest, Romania, in 1994. Also, he received PhD. degree in Transportation from the Politehnica University of Bucharest, Romania, in 2001. Currently, he is Associate Professor of Mechanical Engineering at the Mechanism and Robot Theory Department of the Engineering and Management of the Technological Systems Faculty, Politehnica University of Bucharest, Romania. His research interests include, but are not limited to, the mechanism design, modeling and simulation (CAD-CAE) on mechanisms and robots, computational kinematics and FEA on mechanisms. He is an observing expert of IFTOMM (International Federation for the Theory of Machines and Mechanisms) Permanent Commission A for Terminology, member of the Romanian Association of TMM and co-chair of the Bucharest branch of Romanian Society of Robotics. He has authored more than 100 journal and conference papers on these topics.

Martin Orečný, Ing. He received M.S. degree in Applied Mechanics from Technical University of Košice in 2012. Currently he is a Ph.D. student at the Department of Applied Mechanics and Mechanical Engineering at the Faculty of Mechanical Engineering of the Technical University of Košice, Slovakia. His research interests include vibroizolation of mechanical and mechatronical systems, vibration control, modelling and optimization of mechanical and mechatronical systems. He has published as an author or co-author 9 journal and conference papers on these topics.

Abdel Elbaghar. Hereceived Bc. degree in Mechanical Engineering from theSlovakTechnical University in Bratislava. Currently he is a student in the final year of study at the Faculty of Mechanical Engineering, Technical University of Košice. 
Abstract: In the paper optimization of the motorcycle rear suspension mechanism is presented. The introduction of a four-bar linkage in the classic rear suspension system, composed of a large fork made up of two trailing arms with two spring damper units, one on each side, inclined at a certain angle with respect to the swinging arm, makes it easier to obtain the desired damping and stiffness characteristics of the suspension system. The geometric parameters of the four-bar linkage (Uni-Trak ${ }^{\circledR}$ design of Kawasaki) are used in the paper as the design variables, which are optimized to obtain desired damping characteristics of the rear suspension system. It enables avoiding hitting suspension bumper stops which causes rider's discomfort and also excessive dynamic loads effecting motorcycle parts. Optimization toolbox for use with MATLAB (sequential quadratic programming) and also genetic algorithms were applied to solve the optimization problem. The analysis of numerical results shows that a possibility of varying just one geometric parameter of the four-bar linkage enables tuning the suspension system to different kinds of uneven roads (with different stochastic characteristics).

Keywords: Motorcycle suspension; optimization; four-bar linkage; Uni-Trak ${ }^{\oplus}$ design of Kawasaki; damping force; kinematic analysis

\section{Introduction}

From a dynamics point of view a motorcycle with suspension can be considered as a rigid body connected to the wheels with elastic and damping elements (front and rare suspension). The rigid body constitutes the sprung mass (composed of chassis, engine, steering head and rider). while the wheels and masses attached to them constitute the unsprung masses [1].

Motorcycle suspension has to satisfy the following main purposes:

- allow the wheels to follow the road profile without transmitting excessive oscillations to the rider. This purpose concerns comfort of the rider - the isolation of the sprung mass from the oscillations generated by the interaction of the wheels with the road irregularities;

- ensure wheel grip on the road in order to transmit the required driving, braking and lateral forces;

- ensure the desired trim of the motorcycle rider under various operating conditions - acceleration, braking, entering and exiting turns.

The degree of required comfort varies according to the use of the motorcycle. For example, in the case of racing motorcycles, comfort is less important than its capacity to keep the wheels in contact with the ground and assure the desired trim. In off-road motorcycles the suspension system isolates the sprung mass from impacts generated by motorcycle jumps.

Problem of damping, types of hydraulic dampers and their characteristics, testing of dampers and other advanced problems are comprehensively described in [3]. In [7] a grey-box model of a racing motorcycle mono-tube shockabsorber is proposed, which consists of a nonlinear parametric model and a black-box neural-network-based model. The absorber model has been implemented in a numerical simulation environment, and validated against experimental test data. Simulation and experimental validation of motorcycle dynamic characteristics for displacement-sensitive shock absorber using fluid-flow modelling is presented in [8]. In [9] preloaded liquid spring/damper based shock isolation systems suitable for heavy load military applications are investigated taking into account coupled hydrodynamic and thermodynamic phenomena. Sharma and Limbeer in [10] and [17] present a design methodology for the suspension system of a novel aerodynamically efficient motorcycle. The influence of compliant chassis components on motorcycle dynamics is detailed in [11]. Dynamics of turn behaviours of motorcycles is studied in [12] and [13]. Problems of motorcycle lateral dynamics, steering and traction are presented in [14], [18] and [20]. Rider's effects on the motion of a motorcycle are presented in papers [15], [16] and [19]. Optimization of passive vehicle suspension systems for improving the ride comfort is investigated e.g. in [21].

In the following chapters of the paper optimization of the motorcycle rear suspension mechanism will be presented. As design variables the geometric parameters of the four-bar linkage (added to the classic rear suspension system) are used. The objective functions express the desired progressive characteristics of the passive hydraulic damper. Geometric constraint on the four-bar linkage (enabling its feasibility) is taken into account. Numerical realization of the kinematic 


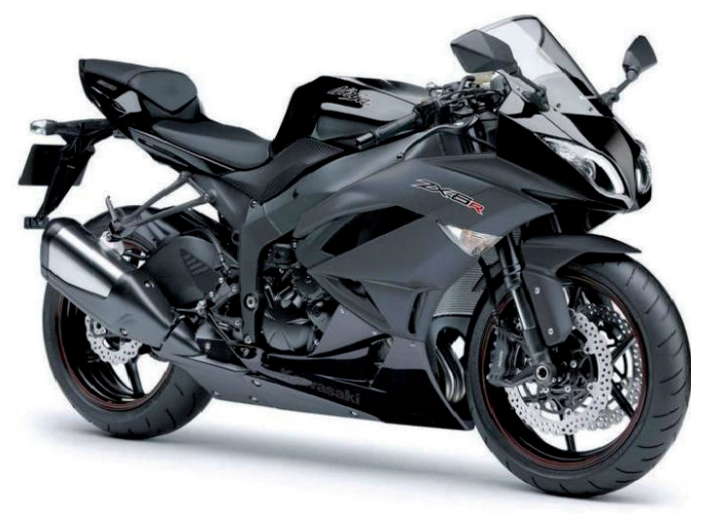

Fig. 1: Kawasaki Ninja ZX-6R ABS.

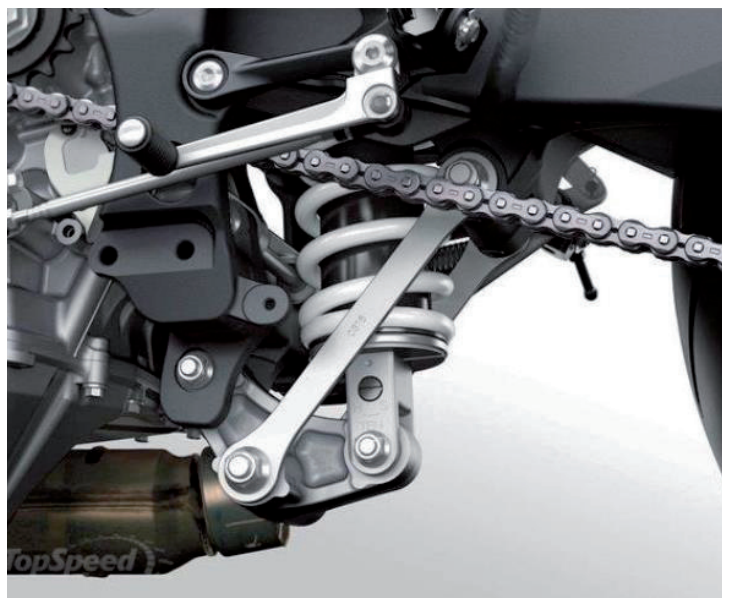

Fig. 2: Four-bar linkage suspension mechanism (Uni-Trak ${ }^{\oplus}$ design of Kawasaki) of motorcycle Kawasaki Ninja ZX-6R ABS. analysis and optimization was carried out in Matlab [2], [5], [6] and also in Working Model 2D [4]. For example motorcycle Kawasaki Ninja ZX-6R ABS is equipped with such a four-bar mechanism (UniTrak $^{\circledast}$ design of Kawasaki). The entire motorcycle is presented in Fig. 1 and its four-bar linkage suspension mechanism can be seen in Fig. 2 .

\section{Kinematic analysis of the rear suspension mechanism}

The kinematic scheme of the rear suspension system illustrating the connectivity of links and joints of the system is shown in Fig. 3. The suspension system is composed of the classic swinging arm (2) with the rear wheel at its right end (not drawn in the figure), the spring-damper unit (5) and the rocker (4) which together with the conecting rod (3), the swinging arm (2) and the chassis (1) form the four-bar linkage (Unitrak design of Kawasaki). The spring-damper unit (5) is inserted between the motorcycle chassis (1) and the rocker (4) at its point $\mathrm{E}$.

In the classic suspension system the introduction of a linkage in the rear suspension system makes it easier to obtain desired damping and stiffness characteristics. These linkages are generally based on the four-bar linkage. They differ only in the different attachment points of the spring damper unit which can be inserted between the chassis and the rocker (Uni-Trak ${ }^{\circledR}$ design of Kawasaki), between the connecting rod and the chassis (Pro_

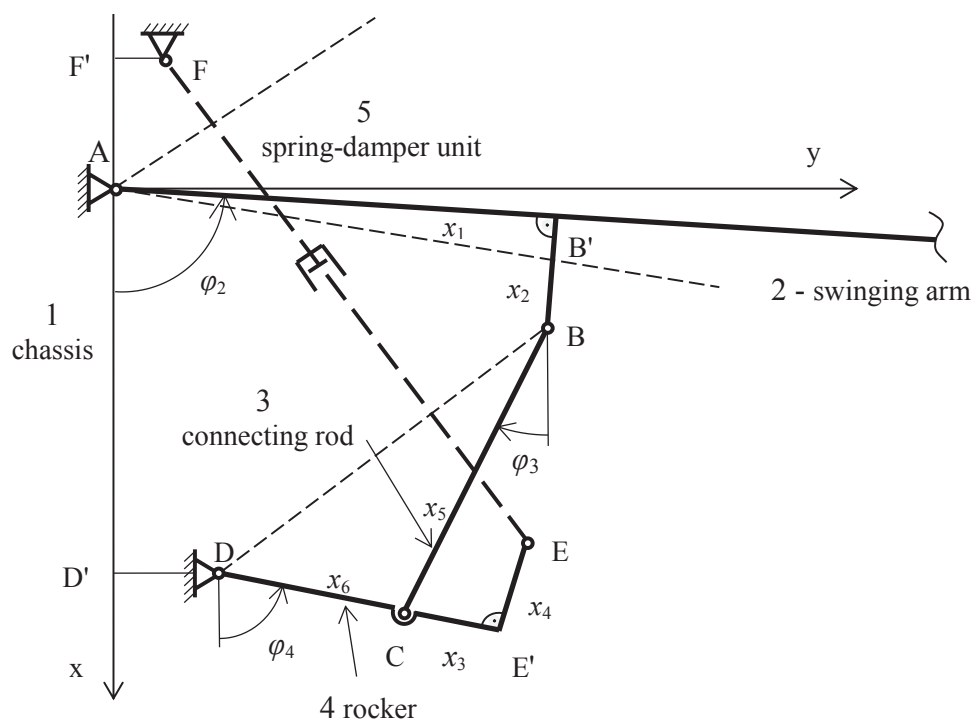

Fig. 3: Kinematic scheme of the rear suspension system. 
link design of Honda) or between the swinging arm and the rocker (Full Floater design of Suzuki). There exist also other different designs (Yamaha, Elf Honda GP, Morbidell 500 C), see e.g. [3].

Kinematic analysis of the rear suspension mechanism in Fig. 3 consists in determining the motion of the point $E$, because the position of the point $F$ on the chassis is fixed. It will enable determining the rate of compression of the damper inserted between the point $\mathrm{E}$ and $\mathrm{F}$ and also determining the damping force. The input motion is uniform circular motion of the swinging arm (2) around point A (at constant angular velocity $\omega_{2}$ ). The distances between individual points will be denoted by a single letter $\mathrm{x}_{\mathrm{i}}$ : $\mathrm{AB}^{\prime} \equiv x_{1}$, $\mathrm{B}^{\prime} \mathrm{B} \equiv x_{2}, \mathrm{BC} \equiv x_{5}, \quad \mathrm{DC} \equiv x_{6}, \quad \mathrm{CE}^{\prime} \equiv x_{3}$ and $\mathrm{E}^{\prime} \mathrm{E} \equiv x_{4}$, see Fig.3. These variables will be used in optimization as the geometric design variables.

To solve the problem of kinematic analysis the vector method will be used. The polygon A-B'-BC-D-D'-A can be assigned to the kinematic scheme of the rear suspension in Fig. 3. The geometric vectors assigned to the polygon sides form a closed geometric figure for which the following vector condition of closeness can be written

$\overrightarrow{\mathrm{AB}^{\prime}}+\overrightarrow{\mathrm{B}^{\prime} \mathrm{B}}+\overrightarrow{\mathrm{BC}}+\overrightarrow{\mathrm{CD}}+\overrightarrow{\mathrm{DD}^{\prime}}+\overrightarrow{\mathrm{D}^{\prime} \mathrm{A}}=\overrightarrow{0}$

Two scalar conditions (in the directions of $x$ and $y$ axes, Fig. 3) can be written from the vector equation (1)

$$
\begin{aligned}
& x: \quad x_{1} \cos \varphi_{2}+x_{2} \sin \varphi_{2}+x_{5} \cos \varphi_{3}-x_{6} \cos \varphi_{4}-\overline{\mathrm{D}^{\prime} \mathrm{A}}=0, \\
& y: \quad x_{1} \sin \varphi_{2}-x_{2} \cos \varphi_{2}-x_{5} \sin \varphi_{3}-x_{6} \sin \varphi_{4}-\overline{\mathrm{DD}^{\prime}}=0 .
\end{aligned}
$$

The above two equations are nonlinear algebraic equations which will be solved for the unknown angle variables $\varphi_{3}$ and $\varphi_{4}$ using Matlab. The input angle variable $\varphi_{2}$ is given in the form (uniform circular motion of the swinging arm)

$$
\varphi_{2}=\omega t
$$

where $\omega_{2}$ is the constant angular velocity of the swinging arm (2), Fig. 3. The distances $\overline{\mathrm{D}^{\prime} \mathrm{A}}$ and $\overline{\mathrm{DD}^{\prime}}$ are supposed to be specified variables (design considerations).

After solving the angle variables $\varphi_{3}$ and $\varphi_{4}$ from eqs. (2) and (3) the following equations can be used to determine the positions of the point $\mathrm{E}$

$$
\begin{aligned}
& x_{\mathrm{E}}=\left(x_{6}+x_{3}\right) \cos \varphi_{4}-x_{4} \sin \varphi_{4}+\overline{\mathrm{AD}^{\prime}}, \\
& y_{\mathrm{E}}=\overline{\mathrm{D}^{\prime} \mathrm{D}}+\left(x_{6}+x_{3}\right) \sin \varphi_{4}+x_{4} \cos \varphi_{4} .
\end{aligned}
$$

The distance of the points $\mathrm{E}$ and $\mathrm{F}$ (the end points of the spring-damper unit) then is

$$
\overline{\mathrm{EF}}=\sqrt{\left(x_{\mathrm{E}}-x_{\mathrm{F}}\right)^{2}+\left(y_{\mathrm{E}}-y_{\mathrm{F}}\right)^{2}},
$$

where the coordinates of the point $\mathrm{F}$ are supposed to be given (at the motorcycle chassis).

\section{Formulation of the optimization problem}

As already mentioned, the optimization task consists in finding the optimal values of the design variables $x_{\mathrm{i}}$ (described in the previous chapter) which ensure the desired damping characteristic of the hydraulic damper. The optimum course of the damper compression will have the following linear and quadratic progressive forms

$v_{\mathrm{d}}=-a-b t$,

and

$v_{\mathrm{d}}=-a-b t-c t^{2}$,

where $a, b$ and $c$ are specified constants. The swinging arm (2) gets from its initial position to its final in time $\mathrm{T}$ which is determined by the following equation

$T=\frac{\varphi_{2 f}-\varphi_{2 i}}{\omega_{2}}$.

The objective function of the optimization problem (see e.g. [22], [23]) can now be formulated in the form (the same for both desired progressive velocities of damper compression (8a) and (8b))

$f_{o p}=\int_{0}^{T}\left(v_{d}-v_{a c t}\right)^{2}$,

where $v_{\text {act }}$ is the actual velocity of damper compression and $v_{\mathrm{d}}$ is the required velocity of damper compression.

In order to ensure feasibility of the four-bar 
linkage in the rear suspension the following constraint has to be taken into account

$x_{6}+x_{5} \geq \overline{\mathrm{BD}}+\overline{\mathrm{BD}}_{\min }$, where $\overline{\mathrm{BD}}_{\text {min }}$ is a safety length. This inequality must be fulfilled in the whole interval of the swinging arm motion.

Table 1: Search intervals.

\begin{tabular}{|c|c|c|c|c|}
\hline Design variable & $\begin{array}{l}\text { Lower bound } \\
{[\mathrm{m}]}\end{array}$ & $\begin{array}{l}\text { Upper bound } \\
{[\mathrm{m}]}\end{array}$ & $\begin{array}{c}\text { Optimal value } \\
\text { (linear required velocity) [m] }\end{array}$ & $\begin{array}{c}\text { Optimal value } \\
\text { (quadratic required velocity) [m] }\end{array}$ \\
\hline $\mathrm{x} 1$ & 0.09 & 0.145 & 0.10000 & 0.10008 \\
\hline$x 2$ & -0.015 & 0.045 & 0.02612 & 0.02016 \\
\hline$\times 3$ & 0.01 & 0.045 & 0.01539 & 0.00463 \\
\hline$\times 4$ & -0.01 & 0.05 & -0.00596 & -0.01529 \\
\hline$\times 5$ & 0.06 & 0.10 & 0.09897 & 0.09035 \\
\hline$x 6$ & 0.06 & 0.11 & 0.09315 & 0.08014 \\
\hline
\end{tabular}

\section{Results of optimization}

The following variables are specified: $\omega_{2}=2 \mathrm{rad} / \mathrm{s}$... swinging arm angular velocity, $\varphi_{2 i}=80^{\circ} \ldots$ swinging arm initial position, $\varphi_{2 f}=105^{\circ} \ldots$ swinging arm final position, $\mathrm{a}=0,145 \mathrm{~m} / \mathrm{s}, \mathrm{b}=0,275 \mathrm{~m} / \mathrm{s}^{2}, \mathrm{c}=0,4 \mathrm{~m} / \mathrm{s}^{3}$. constants determining the required velocity of damper compression,

$\overline{\mathrm{AD}^{\prime}}=0.115 \mathrm{~m}, \overline{\mathrm{DD}^{\prime}}=0.025 \mathrm{~m}$, see Fig. $3, \overline{\mathrm{BD}}_{\min }=0.005 \mathrm{~m}$ (safety length in eq. (11)), $x_{F}=-0.04 m, y_{F}=0.02 m \ldots$ coordinates of the point F, see Fig. 3.

Table 1 gives the search intervals for the design variables of the optimization problems and also optimization results for both variants - with linear and also quadratic required damper compression velocity.

The value of the objective function was $f_{o p}=2.13 \times 10^{-7}$ (for linear required damper velocity) and $f_{o p}=8.76 \times 10^{-6}$ (for quadratic required damper velocity). The constraints were fulfilled in the whole interval of the swinging arm motion.

For numerical optimization genetic algorithms [6] and also deterministic optimization function fmincon based on sequential quadratic programming [5] were used. Genetic algorithms were proved to be more reliable in finding the global optimum of the optimization problem.

Fig. 4 presents dependence of both linear and quadratic progressive actual velocity of damper compression on the input angular displacement of the swinging arm. Both the actual velocities are very close to the required ones determined by eqs. (8a) and (8b).

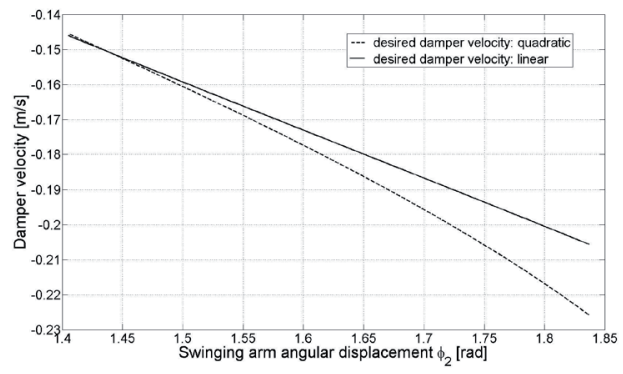

Fig. 4: Dependence of the actual damper velocity on the swingin arm angular displacement.

Fig. 5 illustrates dependence of damping force on the input angular displacement of the swinging arm. It can be seen that the damping forces are significantly greater at the final position of the swinging arm.

Optimal dimensions of the four-bar linkage in the rear motorcycle suspension system were used to model the suspension mechanism in the computer programme Working Model 2D [4]. The

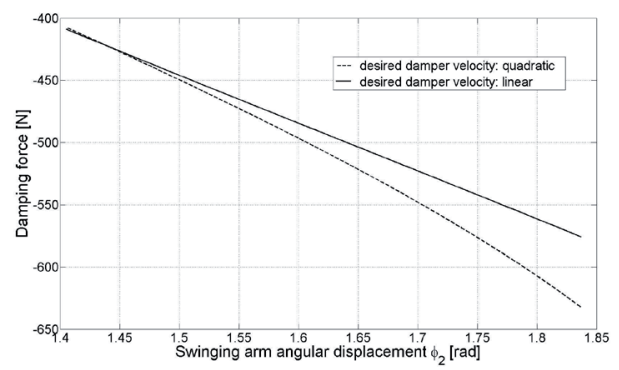

Fig. 5: Dependence of damping force on the swingin arm angular displacement. 
results of modelling proved corectness of the results obtained by Matlab.

Analysis of the dependence of the actual velocity of damper compression on the swinging arm angular displacement $\varphi_{2}$ showed a possibility to control this dependence by varying just one geometric parameter. For example by varying the parameter $x_{1}\left(\overline{\mathrm{AB}^{\prime}}\right)$, Fig. 3, different dependences of the damper compression velocity can be obtained, Fig. 5. Decreasing the parameter $x_{1}$ leads to increasing the damper compression velocity and consequently to increasing damping force and on the contrary.

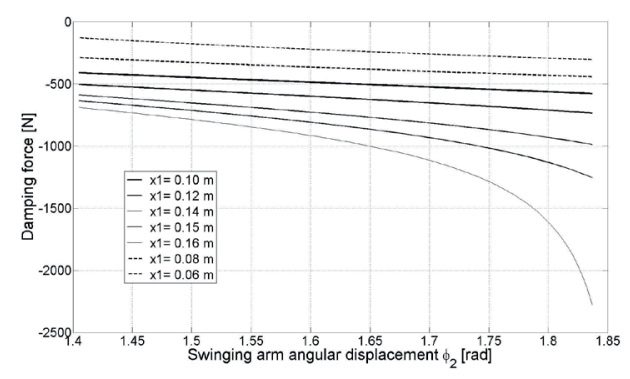

Fig. 6: Dependence of the damper compression velocity on the swingin arm angular displacement $\varphi_{2}$ for varying parameter $x_{1}$.

\section{Conclusion}

Optimization of the geometric parameters of the four-bar linkage added to the swinging arm of the classic motorcycle rear suspension ensures required progressive dependence of the damper compression velocity (and also damping force) on the swingin arm angular displacement. It enables avoiding hitting suspension bumper stops which causes rider's discomfort and also excessive dynamic loads effecting motorcycle parts. Moreover, the paper presents a very useful (especially for race motorcycles) possibility to control this dependence by varying just one geometric parameter of the four-bar linkage. This enables simple (including the design point of view) adaptation of the rear suspension damping characteristic to different kinds of roads or terrain.

\section{Acknowledgments}

This work was supported by grant project VEGA No. 1/1205/12.

\section{References}

[1] Cossalter, V. (2006). Motorcycle Dynamics. LULU.com, Padova.

[2] Bartko, R., Miller, M. (2006). MATLAB I. Algoritmizácia a riešenie úloh. Digital Graphic, Trenčín.

[3] Bradley, J. (1996). The Racing Motorcycle: A Technical Guide for Constructors. Broadland Leisure Publications, Malvern.

[4] Working Model 2D User's Manual (1996). Knowledge Revolution, San Mateo.

[5] Optimization Toolbox for Use with MATLAB, User's Guide (2000).

[6] Genetic Algorithm and Direct Search Toolbox for use with MATLAB (2004). The MathWorks, Natick.

[7] Beghi, A., Liberati, M., Mezzalira, S., Peron, S. (2007). Greybox modelling of a motorcycle shock absorber for virtual prototyping applications. Simulation Modeling Practice and Theory, 15, 894-907.

[8] Lee, Ch.T., Moon, B.Y. (2006). Simulation and experimental validation of vehicle dynamic characteristics for displacement-sensitive shock absorber using fluid-flow modelling. Mechanical Systems and Signal Processing, 20, 373-388.

[9] Samantaray, A.K. (2009). Modeling and analysis of preloaded liquid spring/damper shock absorbers. Simulation Modeling Practice and Theory, 17, 309-325.

[10] Sharma, A., Limebeer, D.J.N. (2012). Dynamic stability of an aerodynamically efficient motorcycle. Vehicle System Dynamics, 50, 8, 1319-1340.

[11] Lake, K., Thomas, R., Williams, O. (2012).. The influence of compliant chassis components on motorcycle dynamics: an historical overview and the potential future impact of carbon fibre. Vehicle System Dynamics, 50, 7, 1043-11052.

[12] Sharp, R.S. (2012). Rider control of a motorcycle near to its cornering limits. Vehicle System Dynamics, 50, 8, 1193-1208.

[13] Karanam, V.M:; Chatterjee, A. (2011). Common underlying steering curves for motorcycles in steady turns. Vehicle System Dynamics, 49, 6, 931-948.

[14] Teerhuis, A.P., Jansen, S.T.M: (2012). Motorcycle state estimation for lateral dynamics. Vehicle System Dynamics, $50,8,1261-1276$

[15] Zhu, S., Murakami, S., Nishimura, H. (2012). Motion analysis of a motorcycle taking intu account the rider's effects. Vehicle System Dynamics, 50, 8, 1225-1245.

[16] Working Model 2D User's Manual (1996). Knowledge Revolution, San Mateo.

[17] Sharma, A., Limebeer, D.J.N. (2012). Motorcycle design using matrix inequalities and passivity constraints. Vehicle System Dynamics, 50, 3, 377-393.

[18] Massaro, M., Sartori, R., Lot, R. (2011). Numerical investigation of engine-to-slip dynamics for motorcycle traction control 
applications. Sharma, A., Limebeer, D.J.N. (2012). Dynamic stability of an aerodynamically efficient motorcycle. Vehicle System Dynamics, 49, 3, 419-432.

[19] Massaro, M. (2011). A nonlinear virtual rider for motorcycles. Sharma, A., Limebeer, D.J.N. (2012). Dynamic stability of an aerodynamically efficient motorcycle. Vehicle System Dynamics, 49, 9, 1477-1496.

[20] Fujii, S. Shiozawa, S., Shinagawa, A., Kishi, T. (2012). Sharma, A., Limebeer, D.J.N. (2012). Dynamic stability of an aerodynamically efficient motorcycle. Vehicle System Dynamics, 50, 8, 1277-1295.

[21] Segla, Š. (2004). Optimization of passive vehicle suspension systems for improving the ride comfort. Acta Mechanica Slovaca, 8, 3C, 161-170.

[22] Segla, Š., Hroncová, D. (2002). Statical balancing of a manipulator with a spring balancing mechanism. Acta Mechanica Slovaca, 6, 3, 83-90.

[23] Seglaa, Š., Poláková, Z., Hroncová, D. (2002). Optimization of statical balancing of a manipulator with varying loads. Acta Mechanica Slovaca, 6, 1, 71-80. 
Acta Mechanica Slovaca

Journal published by Faculty of Mechanical Engineering - Technical University of Košice 